\title{
Extrarenal nephroblastomatosis in children: a report of two cases
}

\author{
Yi Wu' ${ }^{1}$, Xueming Zhu ${ }^{1,3^{*}}$, Xingdong Wang ${ }^{1}$, Hangzhou Wang ${ }^{2}, \mathrm{Xu} \mathrm{CaO}^{2}$ and Jian Wang ${ }^{2,3}$
}

\begin{abstract}
Background: Extrarenal nephroblastomatosis is a rare entity which occurs in retroperitoneum and inguinal region predominantly. Here we report two cases of primary extrarenal nephroblastomatosis of Han Chinese in Asian in unusual locations, one is located in testis and paratestis, and the other is paraspinal cord.

Case presentation: Patient 1 was a 19-month-old boy with a hard and nodular mass adherent to the left testis in inguinal region. Patient 2 was a 9-month-old boy with a $1 \times 0.7 \times 0.4 \mathrm{~cm}$ mass in spinal canal at the midline thoracolumbar region. Histological examinations of the two patients after operations revealed extrarenall nephroblastomatosis with multiple nephrogenic foci, composed of immature glomeruli, tubules and blastemal cells.Then the patients were closely monitored without adjuvant chemotherapy, and has been alive and well without any recurrence for $>6$ months.

Conclusions: Most nephrogenic rests remain subclinical, and thus, complete excision of the lesion with conservative treatment is recommended. Otherwise, nephrogenic rests are close associated with Wilms tumor and regular follow-up is required to ensure early detection of malignant transformation.
\end{abstract}

Keywords: Extrarenal nephroblastomatosis, Nephrogenic rests, Paratestis, Paraspinal cord

\section{Background}

Extrarenal nephroblastomatosis, also called ectopic immature renal tissue (EIRT) [1-3], extrarenal nephrogenic rest (ENR) $[4,5]$, hamartoma with primitive renal tissue [4] and mesonephric remnant tissue [2], has been reported only rarely in the world literature. This unusual lesion is often associated with extrarenal Wilms tumor. However, the mechanism underlying the development and persistence of extrarenal nephrogenic rests remains unclear.

We retrospectively reviewed our hospital records of the past 10 years for cases of nephroblastomatosis and nephroblastoma (Wilms tumor), and identified only two cases of extrarenal nephroblastomatosis, one in the inguinal canal and the other in the vertebral canal. Here, we describe the clinical characteristics, diagnosis, treatment and embryological implications in these two cases.

\footnotetext{
* Correspondence: xueming_zhu@aliyun.com

'Department of Pathology, Soochow University Affiliated Children's Hospital, Jiangsu 215003, China

${ }^{3}$ Institute of Pediatric Research, Soochow University Affiliated Children's

Hospital, Jiangsu 215003, China

Full list of author information is available at the end of the article
}

\section{Case presentation \\ Case 1}

A 19-month-old boy of Han Nationality presented with an impalpable undescended left testis and the ultrasound examination revealed left cryptorchidism. Regular physical, biochemical and imaging examinations didn't show any other abnormality then the patient underwent a left orchiopexy and the testis, which measured $0.8 \times 0.5 \times$ $0.3 \mathrm{~cm}$, was found in the inguinal canal, along with a hard, undetachable, nodular mass, intimately adherent to the testis and epididymis. A portion of the mass was excised and subjected to frozen section analysis, but the result was inconclusive for a potential malignant lesion. A radical left orchiectomy was therefore performed. Examination of the resected specimen showed that the mass had invaded the testicular tissue but not the tissues surrounding the testis. Microscopic examination of paraffin-embedded tissue sections revealed that the part of the mass attached to the testis contained fibrous tissue with multiple foci of nephrogenic tissues, which were composed of immature glomeruli, tubules and blastemal cells. Within the nephrogenic tissue, mitotic figures were infrequent, and none of the mitotic figures observed were atypical (Figure 1A,B). And the other 


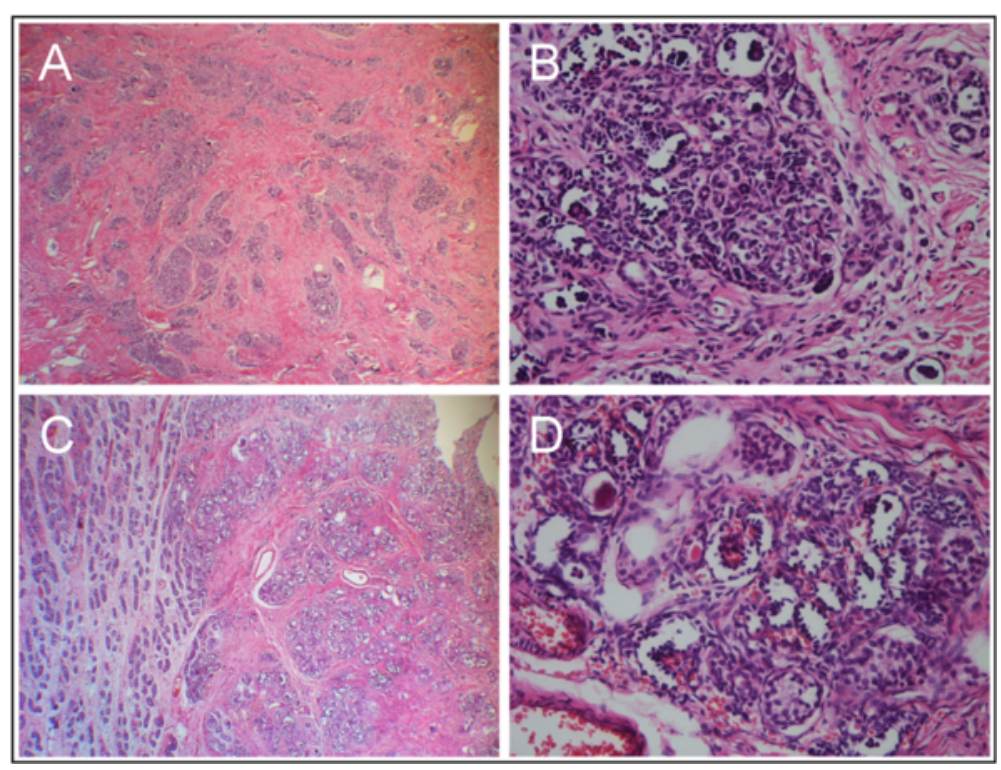

Figure 1 Testicular nephrogenic rest in the inguinal canal. A. The paratesticular mass is a complex containing fibrous tissues and multiple nephrogenic foci (hematoxylin and eosin; $\times 40$ ). B. Nephrogenic foci are composed of immature glomeruli, tubules and blastemal cells (hematoxylin and eosin; $\times 400$ ). C. The mass in testis contains nephrogenic foci adjacent to seminiferous tubules and rete testis (hematoxylin and eosin; $\times 40$ ). D The lesion consistes of undifferentiated blastemal tissue, abortive glomeruli and dysplastic tubules with intervening testicular tissue (hematoxylin and eosin; $\times 400)$.

part of the lesion in the testis consisted of undifferentiated blastemal tissue, abortive glomeruli and dysplastic tubules with intervening testicular tissue. The seminiferous tubules and rete testis were adjacent to the nephrogenic rests, and the testicular development was appropriate for the patient's age. No definitive invasive component was found in the lesion (Figure 1C,D). A multidisciplinary team, after some discussion, arrived at a final pathological diagnosis of extrarenal nephroblastomatosis, although the diagnosis of nephroblastoma could not be completely excluded. Postoperatively, conservative treatment was administered along with followup ultrasound examinations and clinical reviews. The patient continues to be asymptomatic for more than 6 months.

\section{Case 2}

A 9-month-old boy of Han Nationality presented with an oval mass measuring $6 \times 5 \times 4 \mathrm{~cm}$ on his back, in the midline thoracolumbar region. The lesion was covered with normal skin. Magnetic resonance imaging (MRI) revealed a vertebral malformation with meningomyelocele, diastematomyelia and tethered cord syndrome (Figure 2A). On physical examination, knee jerk, muscular tension and muscle strength were found to be normal, and pathological reflexes were absent. No abdominal visceral or other abnormalities were detected. The patient underwent repair of meningomyelocele and diastematomyelia, and lysis of the tethered cord under general anesthesia. During the operation, we found a $1 \times 0.7 \times 0.4 \mathrm{~cm}$ mass just adherent to the surface of the spinal cord at the T7-L1 level. On pathological examination, this mass was found to consist of a blastemal component and nephrogenic epithelial tubular and rudimentary glomeruloid structures, resembling immature ectopic nephrogenic tissue, with occasional neurogenic tissue and dystrophic calcifications. Mitoses were rare, and none of those observed were atypical (Figure 2B,C,D). The pathological diagnosis was extrarenal nephroblastomatosis without evidence of a neoplastic process. The lesion appeared to have been completely excised. Multiple pediatric experts recommended close observation without adjuvant chemotherapy. The patient has been alive and well without any evidence of recurrence or malignant transformation for over 6 months.

\section{Discussion}

Kidney development, which is also called nephrogenesis, is a complex process involving tissues with two distinct embryological origins: nephrogenic and ductogenic [6]. Nephrogenic tissue develops from the intermediate mesoderm and proceeds through a series of three successive phases: pronephros, mesonephros and metanephros. This process normally ceases after 36 weeks of gestation, at which time, the metanephric blastema in the kidney disappears [7]. Occasionally, the nephrogenic blastema fails to mature into normal renal parenchyma, and the persistent blastemal tissue is then referred to as nephrogenic rests, 


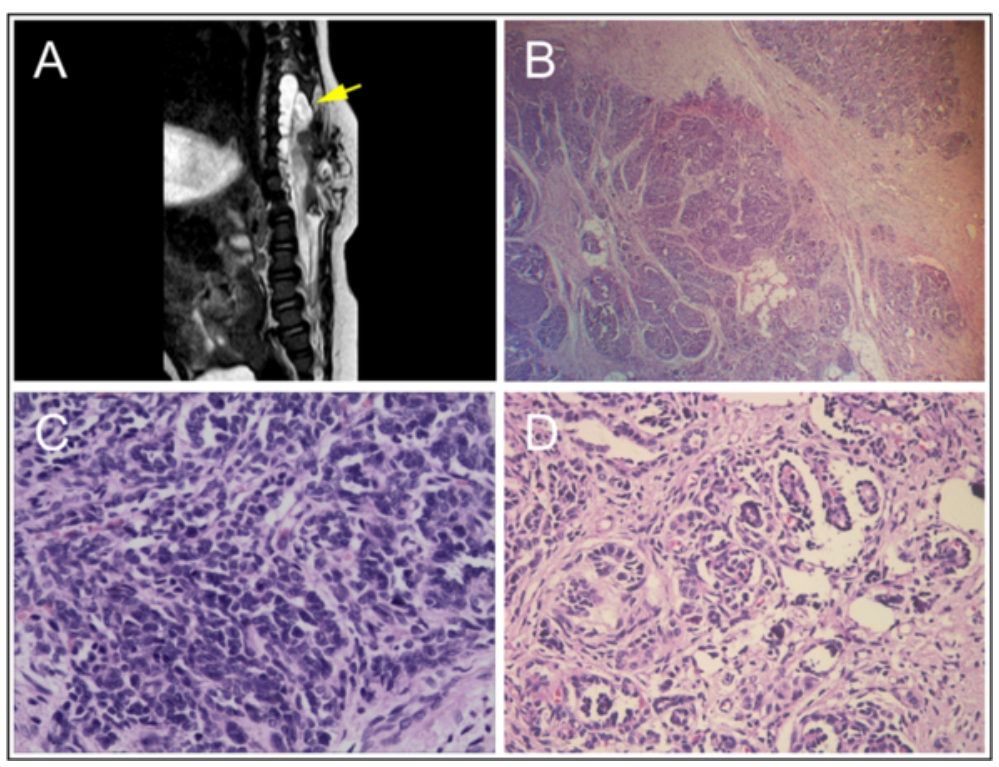

Figure 2 Intraspinal nephrogenic rest in the thoracolumbar region. A. Magnetic resonance image of a vertebral body malformation. The arrow indicates the mass. B. The intraspinal mass contains nervous tissues and multiple nephrogenic foci (hematoxylin and eosin; $\times 40$ ). C. Blastemal component of the mass (hematoxylin and eosin; $\times 400$ ). D. Nephrogenic epithelial structures (nephric tubular and glomeruli) in the mass (hematoxylin and eosin; ×400).

which may undergo oncogenic mutation to form a malignant embryonal tumor known as nephroblastoma. On histological examination, nephrogenic rests usually appear as aggregates of abnormally persistent embryonal nephroblastic tissue with small clusters of blastemal cells, tubules and occasional glomeruli, with a variable amount of admixed fibrous stroma. Nephrogenic rests can be unifocal, multifocal or diffuse. The term nephroblastomatosis is used to refer to diffuse or multifocal nephrogenic rests or their derivatives [8]. Nephrogenic rests can be subclassified into perilobar nephrogenic rests and intralobar nephrogenic rests, according to their location in relation to the renal lobe on histological examination. Occasionally, nephrogenic rests are found in ectopic sites, such as the inguinal canal [5], lumbosacral area [3,9-12], adrenal gland [13], thorax [14,15], colon [16] and heart [17]. There are two possible distinct fates for nephrogenic rests: to be an isolated developmental abnormality, or the early stage of a neoplastic process, with the latter being more clinically significant. Most nephrogenic rests become dormant, mature or spontaneously regress. Some undergo hyperplastic overgrowth, which is hypothesized to be an intermediate, pre-neoplastic stage in the process of tumorigenesis. Only a small number undergo a neoplastic induction to transform into Wilms tumor, which is the most common malignant renal neoplasm in children [18].

Differential diagnosis between extrarenal nephroblastomatosis and extrarenal nephroblastoma is mandatory when ectopic immature renal tissue is found. Sometimes it is difficult to distinguish ectopic nephrogenic rests from Wilms tumor on histology, and it is especially difficult to distinguish between a proliferative nephrogenic rest and a small Wilms tumor [19]. Generally, nephroblastoma tends to form round nodules enclosed in a fibrous pseudocapsule owing to its rapidly expansile growth. On histological examination, the lesion comprises nephrogenic tissues, such as blastemal, epithelial (tubular and glomeruloid) and mesenchymal elements. The distinguishing characteristic of nephroblastoma is frank atypia including disordered structures, atypical mitoses and marked pleomorphism. Otherwise, approximately $5 \%$ of Wilms tumors show anaplastic cells, which is a typical characteristic of malignant, indicating poor prognosis [20,21]. In contrast, the lesion in nephroblastomatosis usually consists of small multiple microscopic nests and islets. Mitoses are usually sparse, except in proliferative nodules, which exhibit high mitotic rates and moderate pleomorphism, but no obvious atypia. Proliferative nephrogenic rests invariably show striking enlargement, but lack the peritumoral pseudocapsule characteristic of Wilms tumor.

In both our patients, the possible differential diagnoses included teratoma, a neoplasm originating from testicular tissue, metastasis and malignancies other than Wilms tumor. The nephrogenic epithelial elements (glomeruli, tubules) in the two cases had differentiated to a rather advanced degree, and rare mitoses with no atypia were found scattered within the dense fibrous tissue, indicating a benign neoplasm. The 
diagnosis of teratoma was excluded due to the lack of other teratomatous non-nephrogenic tissues.

The ectopic nephrogenic rests were thought to have originated from mesonephric or metanephric tissue. In the few published studies on this topic, ectopic nephrogenic rests have been reported predominantly in the retroperitoneum and inguinal region [22]. In our first patient, the mass was attached to the testis, which is consistent with an nephrogenic rest arising from mesonephric tissue, because the mesonephros is associated with the developing gonad, embryologically [23]. There have also been several case reports of intraspinal nephrogenic rests located in the lumbosacral area and frequently associated with spinal dysraphism [3,10]. This peculiar association of spinal abnormalities with nephrogenic rests in the lumbosacral region, where the metanephros comes closest to the spinal cord [24], supports the hypothesis that neural tube abnormalities interfere with the migration of renal tissue and thereby result in ectopic nephrogenic rests [4,12]. However, in our second patient, the lesion was located in the lower thoracic region, indicating that nephrogenic remnants may be trapped between the dura and the developing spinal cord early during nephrogenesis.

\section{Conclusions}

From the scarce literature available on this subject, we conclude that most nephrogenic rests can be expected to remain subclinical, and thus, complete excision of the lesion with conservative treatment is recommended. However, it is reported that approximately $40 \%$ Wilms tumors were associated with nephrogenic rests [19]. Owing to the close association between renal nephrogenic rests and Wilms tumor, regular follow-up is required for such lesions until the period of risk has ended. This ensures the detection of malignant transformation at an early stage $[25,26]$.

\section{Consent}

Written informed consent was obtained from the patient's parents for publication of this case report and any accompanying images. A copy of the written consents is available for review by the Editor of this journal.

\section{Ethics}

The materials and data of the patients have been performed in accordance with the Declaration of Helsink and have been approved by an appropriate ethics committee of Soochow University Affiliated Children's Hospital.

\section{Competing interests}

The authors declare that they have no competing interests.

\section{Authors' contributions}

WY contributed to write this article. ZXM, WXD, WHZ, GX and WJ were involved in the diagnostic and clinical management of these patients. All authors read and approved the final manuscript.

\section{Acknowledgement}

The authors are grateful to Mrs Ming Zhang and Xiaowei Li for contributing materials essential for the report.

\section{Author details}

'Department of Pathology, Soochow University Affiliated Children's Hospital, Jiangsu 215003, China. ${ }^{2}$ Department of Pediatric Surgery, Soochow University Affiliated Children's Hospital, Jiangsu 215003, China. ${ }^{3}$ Institute of Pediatric Research, Soochow University Affiliated Children's Hospital, Jiangsu 215003, China.

Received: 24 June 2014 Accepted: 29 September 2014

Published: 6 October 2014

\section{References}

1. Goldberg J, Drut R: Ectopic immature renal tissue. Report of two cases. Pathol Res Pract 1984, 179(1):115-123.

2. Ducos R, Warrier RP, MacKenzie F, Evans B: Ectopic immature renal tissue in an infant with undescended testis. Am J Pediatr Hematol Oncol 1986, 8(3):264-266.

3. Alston SR, Fuller GN, Boyko OB, Goscin SA, DiSclafani A: Ectopic immature renal tissue in a lumbosacral lipoma: pathologic and radiologic findings. Pediatr Neurosci 1989, 15(2):100-103.

4. Abrahams JM, Pawel BR, Duhaime AC, Sutton LN, Schut L: Extrarenal nephroblastic proliferation in spinal dysraphism. A report of 4 cases. Pediatr Neurosurg 1999, 31(1):40-44.

5. Bennett S, Defoor W, Minevich E: Primary extrarenal nephrogenic rest. J Urol 2002, 168(4 Pt 1):1529.

6. Horster MF, Braun GS, Huber SM: Embryonic renal epithelia: induction, nephrogenesis, and cell differentiation. Physiol Rev 1999, 79(4):1157-1191.

7. Charles AK, Brown KW, Berry PJ: Microdissecting the genetic events in nephrogenic rests and Wilms' tumor development. Am J Pathol 1998, 153(3):991-1000.

8. Beckwith JB, Kiviat NB, Bonadio JF: Nephrogenic rests, nephroblastomatosis, and the pathogenesis of Wilms' tumor. Pediatr Pathol 1990, 10(1-2):1-36.

9. Gaskill SJ, Kagen-Hallett K, Marlin AE: Diastematomyelia associated with ectopic renal tissue. Pediatr Neurosci 1988, 14(2):108-111.

10. Ibrahim AE, Myles L, Lang DA, Ellison DW: Case of the month: June 1998-2 year old boy with lumbosacral mass. Brain Pathol 1998, 8(4):817-818.

11. Posalaky Z, Drake RM, Mawk JR, Franciosi RA, Spencer BH, Athinarayanan PR, Baker TA, Viring N: Ectopic immature renal tissue over the dorsum of lumbar and sacral area in two infants. Pediatrics 1982, 69(3):336-339.

12. Horenstein MG, Manci EA, Walker AB, Dehner LP: Lumbosacral ectopic nephrogenic rest unassociated with spinal dysraphism. Am J Surg Pathol 2004, 28(10):1389-1392.

13. Milliser RV, Greenberg SR, Neiman BH: Heterotopic renal tissue in the human adrenal gland. J Urol 1969, 102(3):280-284

14. Kayiran PG, Gumus T, Kayiran SM, Bilge I, Gurakan B: Ectopic intrathoracic kidney with right-sided congenital diaphragmatic hernia. J Pediatr 2013 163(4):1226-1226. e1221.

15. Onuk O, Tas T, Senturk AB, Sinanoglu O, Balci MB, Celik O, Nuhoglu B: Right-Sided Bochdalek Hernia with Intrathoracic Ectopic Kidney in an Advanced-Age Adult: A Case Report. Urol Int 2014, [Epub ahead of print]

16. Jain D, Martel M, Reyes-Mugica M, Parkash V: Heterotopic nephrogenic rests in the colon and multiple congenital anomalies: possibly related association. Pediatr Dev Pathol 2002, 5(6):587-591.

17. Milliser RV, Greenberg SR, Neiman BH: Heterotopic renal tissue in the human heart. J Urol 1972, 108(1):21-24.

18. Beckwith JB: Precursor lesions of Wilms tumor: clinical and biological implications. Med Pediatr Oncol 1993, 21(3):158-168.

19. Beckwith JB: Nephrogenic rests and the pathogenesis of Wilms tumor: developmental and clinical considerations. Am J Med Genet 1998, 79(4):268-273

20. Vujanic GM, Sandstedt B, Harms D, Kelsey A, Leuschner I, de Kraker J: Revised International Society of Paediatric Oncology (SIOP) working classification of renal tumors of childhood. Med Pediatr Oncol 2002, 38(2):79-82.

21. Breslow NE, Churchill G, Nesmith B, Thomas PR, Beckwith JB, Othersen HB, D'Angio GJ: Clinicopathologic features and prognosis for Wilms' tumor patients with metastases at diagnosis. Cancer 1986, 58(11):2501-2511. 
22. Oottamasathien S, Wills ML, Brock JW 3rd, Pope JCT: Primary extrarenal nephroblastomatosis. Urology 2007, 69(1):184. e183-184.

23. Strand WR, Chou P, Pero JE, Kaplan WE: Extrarenal Wilms tumor occurring in the inguinal canal. J Urol 1990, 143(4):783-785.

24. Summers BA, de Lahunta A, McEntee M, Kuhajda FP: A novel intradural extramedullary spinal cord tumor in young dogs. Acta Neuropathol 1988, 75(4):402-410

25. Caiulo VA, Latini G, Cataldi L, De Felice C: Nephrogenic rests: their frequency and their fate. J Pediatr Hematol Oncol 2007, 29(6):361-363.

26. Hennigar RA, O'Shea PA, Grattan-Smith JD: Clinicopathologic features of nephrogenic rests and nephroblastomatosis. Adv Anat Pathol 2001, 8(5):276-289.

doi:10.1186/1471-2431-14-255

Cite this article as: Wu et al: Extrarenal nephroblastomatosis in children: a report of two cases. BMC Pediatrics 2014 14:255.

\section{Submit your next manuscript to BioMed Central and take full advantage of:}

- Convenient online submission

- Thorough peer review

- No space constraints or color figure charges

- Immediate publication on acceptance

- Inclusion in PubMed, CAS, Scopus and Google Scholar

- Research which is freely available for redistribution 